\title{
A Process Framework For Implementing A Laptop Program
}

\author{
Lori Baker-Eveleth, (Email: leveleth@uidaho.edu), University of Idaho \\ Daniel Eveleth, (Email: eveleth@uidaho.edu), University of Idaho \\ Michael McCollough, (Email: mccollou@uidaho.edu), University of Idaho \\ Scott Metlen, (Email: metlen@uidaho.edu), University of Idaho \\ Michele O'Neill, (Email: moneill@uidaho.edu), University of Idaho
}

\section{INTRODUCTION}

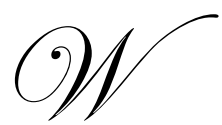

hile early advocates of mandatory student laptop programs could identify sound pedagogical arguments for implementing them a decade ago, most universities were unable to assume the cost burden or allocate the cost to students. Since that time though, rapidly declining technology prices combined with increasingly tight computer lab operating budgets has caused many administrators to reconsider laptop programs. Now, in addition to making good pedagogical sense, laptop programs can simply make "good cents" by freeing up financial resources spent staffing computer labs and maintaining equipment as well as physical resources dedicated to housing computer labs.

Just like a Medusa's head however, a mandatory laptop program can solve budget and space problems but will create new, unintended problems for faculty and students if it is implemented incorrectly. Two years after initiating our own mandatory laptop program and experiencing its results, we want to suggest a process framework for deciding on the correct program and share valuable insights. We believe both administrators and faculty will find the lessons we learned useful as they ponder their own laptop program.

Before discussing the process framework though, it is important that potential users adopt what may be considered a new approach to problem solving. This is because the framework uses a collaborative approach that involves stakeholders throughout a university and is contrary to the way many programs or initiatives in academia are typically implemented. While the approach is not new for businesses - and some faculty teach it in the classroom even - we encountered some resistance to it, probably because it is only relatively recently that universities are being required by state funding agencies, donors, and accreditation boards to prove their efficiency and effectiveness.

The argument then, for involving stakeholders to solve a problem at a university relies on recognizing that the university is now being held accountable in ways similar to those for business organizations. And just as a manager relies on input from staff and employees because the manager does not know everything about everything, academic administrators and faculty must also rely on input from others.

The leap for many universities today then, is for each to recognize that a university is an organization, and an organization is often described as a "problem-facing and problem-solving phenomenon," where managers make decisions using information from "an environment which does not fully disclose the alternatives. . . or (their) consequences." " Environmental dimensions such as complexity and dynamism can create uncertainty that hinders individual decision-makers, who are bounded in their ability to rationally process all information and make optimal decisions. ${ }^{2}$ The greater the complexity and dynamism of the environment the greater the demands placed on decisionmakers. ${ }^{3}$ As a result, organizations must rely more heavily upon cross-functional teams, rather than individuals, to solve complex problems or capitalize on potential opportunities. ${ }^{4,5}$

Furthermore, many organizations have chosen to involve multiple stakeholders to create a collaborative decision-making process. The expectation is that involving stakeholders will lead to greater stakeholder commitment and thus, potentially more effective implementation of any decision outcome. ${ }^{6}$ Again, any administrator, program director, or faculty advocating a laptop program may have the power or resources to implement it, but involving others will promote buy-in and acceptance. Indeed, this foreshadows one of our lessons learned. 
In this paper we share the process framework and insights we developed as a result of using a crossfunctional team with stakeholder involvement to solve a complex problem and capitalize on a related opportunity. The information technology (IT) office of our university was facing a complex problem. The environment was becoming less munificent with respect to financial resources at a time when existing student computing equipment - desktops located in several labs throughout the university - was becoming obsolete. In addition, students and faculty were expressing an interest in mobile computing and a desire to eliminate the place and time restrictions created by the computer lab arrangement. Simultaneously, the College of Business and Economics at the university was exploring computer technology options to be incorporated into the design and construction of its new classroom building. Ultimately, relevant stakeholders collaborated to solve a problem and explore an opportunity. As a result of this collaborative effort, a mandatory laptop program was implemented in the college in which all incoming juniors were required to purchase a designated laptop.

Next is a summary of the individual and group decision-making model literature. The section explains why we chose to use the rational decision making model. Following that, we describe how we used the model as our process framework to both address the IT group's problem and explore the college's opportunity. We also share the lessons we learned about this process, providing some useful insights. Then, we report student survey results as a partial gauge of the initial effects of, and attitudes towards, the laptop program. Last, we offer recommendations for those interested in implementing a laptop program.

\section{THE RATIONAL DECISION-MAKING MODEL}

A commonly accepted conclusion about human decision making is that human beings do not always make rational decisions. ${ }^{7}$ The processes of perception, reasoning, and judgment are constrained by cognitive limitations and by individuals' knowledge and unique experiences that enhance certain individual decision-making biases and tendencies. ${ }^{8}$ Such biases as selective perception, fundamental attribution error, availability bias, the halo effect, and overconfidence limit an individual's ability to make rational decisions. ${ }^{9}$

Decision making can also be hindered by social influence when decisions are made in groups or in naturalistic settings where "decisions are embedded in a broader situational and cultural context." 10 , 11 Unlike individual decision-making, the process of making a decision in groups is often affected by pressures to conform, tendencies to obey authority figures, and attempts to influence others. ${ }^{12,13,14}$ In order to limit the effects of individual and group biases, while capitalizing on the primary benefit of group decision-making, i.e., different perspectives and skills, decision makers often resort to a structured decision making approach to help guide the process. ${ }^{15} \mathrm{We}$ chose to follow this advice by using the Rational Decision Making Model (RDMM) as our framework for reaching a decision.

The RDMM has its roots in work by Dewey and is, in large part, an outcome of studies conducted in the 1950s in a project called the National Training Laboratories. ${ }^{16}$ As a result of the project, Kepner and Tregoe developed the first business-friendly framework for decision making. ${ }^{17}$ The original framework included the following seven steps:

- $\quad$ Define the problem
- $\quad$ Generate criteria
- $\quad$ Generate alternatives
- $\quad$ Compare the scores for the alternatives
- Choose the alternative with the best score

The original seven steps have been modified by others over the years and are often collapsed into 5 or 6 steps, but the spirit of the model remains relatively unchanged. Consistent with later research on the RDMM, we felt that making decisions without reviewing the ramifications of those decisions or adjusting implemented decisions to create better outcomes was a recipe for failure in the future. Thus, we chose to use a modified five step version of the model: 
- $\quad$ Define the problem or opportunity

- $\quad$ Set objectives and criteria for a solution

- $\quad$ Generate alternatives

- $\quad$ Evaluate and select

- Implement, monitor, and adjust

\section{THE PROCESS FRAMEWORK}

\section{Step 1: Define The Problem Or Opportunity}

Three years prior to implementing the laptop program, the IT group had conducted its annual evaluation to forecast budgetary and staffing needs for the next few years. The group concluded that the numerous traditional computer labs for which it was responsible were not only costly to service and maintain, but also due for very expensive hardware and software upgrades. Further, the university had other demands for which the space housing the computer labs could be employed, e.g., office, classroom, and program usage, and a desire to limit the overhead associated with the labs. Moreover, IT believed traditional computer labs were not the direction in which studentcomputing needs were going. After part of the IT staff attended a national conference showcasing technological innovations oriented towards higher education, the IT department concluded that wireless technology and hence, mobile computing, was the area in which money, infrastructure, and support services should be invested.

While the most salient problem for the IT group was resource constraints, a related problem was gaining acceptance of significant change to the present structure from the numerous stakeholders that would be affected. To address this issue, IT believed it needed to involve those administrators and department deans who were willing to listen to possible alternatives. To that end, the IT group organized a visit for decision makers to another university that was currently using wireless technology in conjunction with a required laptop program.

During this same time, the dean for the College of Business and Economics was raising funds from private donors and working with others to develop plans for a new classroom building. The dean faced the rare opportunity to design a building from the ground up that would enhance the learning environment for students and faculty. To gather information about the latest learning technology, he joined the IT group on the planned campus visit. As a result of the trip, the dean decided that at a minimum the new building needed to support wireless technology.

A positive side effect from the campus visit was the mutual awareness that the IT group and the dean had a shared interest. The decision makers concluded that the IT group's problem may have a similar solution as the dean's opportunity, and that implementing the solution on a small scale (i.e., the new building) may be a good testing ground for subsequent changes at the wider-university level. As a result, a committee comprised of IT staff, business faculty, business students and representatives from other university offices and centers, i.e., Registrar, Financial Aid, Purchasing, and Bookstore, was formed to facilitate collaboration. The committee was charged with determining what form of wireless technology would optimize learning in the upcoming business building and developing ideas for how the new building might be a model for campus-wide changes toward a wireless environment in the future.

\section{Step 2: Set Objectives And Criteria For A Solution}

After the committee understood the nature of the problem and challenges of the concurrent opportunity, it then developed objectives. Central to this stage of the process was having a clear understanding of the needs and limitations of the target student population, that is, junior-level business students. After analyzing the cost structure for business students with respect to fees, living expenses, and textbooks, as well as historical trends therein, a dollar cap for the eventual wireless learning tool and all support services was identified. Thus, the first and highest ranking objective was total cost of ownership should not exceed the cap.

The IT group developed two other objectives that were related to the cost objective. The group believed that a primary driver in the total cost of ownership for most technology-based tools was the service component. The IT group knew from experience that there would be significant cash outlays for hiring, training, and staffing a technology support service. Thus, the technology tool of choice needed to be highly durable to reduce percent downtime. This 
objective meant more than just the degree to which a product could withstand physical hardships, such as being tossed in a backpack along with texts, calculators, water bottles, etc. Durability included the ability of the tool to take care of itself to a reasonable degree. For example, the device must be able to maintain itself with self-scans that would invoke patches, updates, or self-diagnosing support programs as necessary.

The other objective tied to the total cost of ownership objective was to minimize costs by choosing a technology product that was easy to service. In this way, the fewer screws, latches, components, or wires that needed to be removed to access primary parts, the less training, time, and staff that would be needed to solve any problem.

Another highly ranked objective was for the tool to enhance learning across the curriculum. The dean and faculty felt strongly that implementing new technology for the new technology's sake alone would be counter productive if the new device was not incorporated into teaching and learning. At this point, the committee could not precisely state the ways in which enhanced learning could be achieved since all the various technology devices had not been proposed yet. However, the objective would be applied during the evaluation phase because the committee believed that faculty and student acceptance of the new tool and its associated procedures was contingent in part upon the perceived value-added in learning from switching to the new technology. In other words, the team recognized that perceived cost needed to be balanced with perceived benefits.

Other objectives were identified with little to no priority ranking. The deadlines for both placing final order requests to a vendor as well as arranging different financing agreements needed to integrate well with student financial aid packages. To accommodate installing software unique to the needs of the business college, the tool needed to be able to implement course-required software easily. In addition, the product vendor needed to work well with the campus bookstore to ensure students and faculty could easily find additional hardware, software, and product accessories. To make software economically feasible, the product needed to come with campus licensing agreements. After meeting curriculum needs with respect to software and hardware within the price limitations, another objective was for the tool to meet student wants - as was practical - regarding sound quality, visuals, ease of use, and memory capacity. The committee believed this would help promote satisfaction with the overall program. A final objective for consideration was related to cataloging the product. The IT group wanted to simplify shipment receipt, minimize student orientation to the tool, and enable inventory tracking when the tool was in for servicing; thus, it was important that the IT staff be able to process the inventory efficiently.

\section{Step 3: Generate Alternatives}

Since the committee was charged with determining what form of technology would optimize learning in the upcoming business building and developing ways in which the new building might be a model for campus-wide changes toward a wireless environment in the future, a variety of technology tools were considered.

Tablet-PCs were identified as one possibility. These were very new products and their characteristics were unknown to many of the committee members at the outset of the process.

Because of the earlier visit to the other university campus, laptops were an obvious alternative. To learn more about choices within laptop programs, various committee members visited other campuses with laptop programs. The most common laptop program options observed included: 1) requiring a laptop with minimum software and hardware specifications and leaving it to the students to select and purchase an appropriate laptop, 2) requiring a specific laptop and software that students purchased directly from a specified vendor, or 3) requiring a specific laptop and software that students purchased or leased directly from the school.

During these campus visits, another alternative was identified, namely personal digital assistants (PDA's). While PDA's had been around for a few years, it was only recently that wireless technology had been incorporated into the tool to provide connectivity. At least one university was supplying a PDA device for its students. 


\section{Step 4: Evaluate And Select}

With identified alternatives the committee conducted in-depth research to evaluate the various products and brands. As part of this research non-committee faculty and students were periodically asked to take part in hands-on demonstrations of the different tools. From the demonstrations, participants were asked to evaluate the tool against the stated objectives and provide feedback to the committee.

The tablet-PC generated the most excitement from the faculty and students, but it failed to meet many of the objectives, e.g., total cost of ownership not exceeding the cap and highly durable. For example, to avoid inputting words and numbers via tapping a pen, which was viewed as time-consuming in a classroom environment, a user inserts the tablet-PC into a small, rotating stand and connects to a keyboard. Because of the delicate nature of these features, the committee believed that the durability objective could not be met by the tablet-PC. In addition, the third ranked objective - enhance learning across the curriculum - was not supported by research articles. Experts in the field of wireless technology were concluding that tablet-PCs worked best within vertical markets and jobs that used checkable forms.

The second alternative was the PDA. The committee determined that while PDA's appeared to satisfy the three highest ranked objectives, other objectives could not be met easily. For example, transferring data or software to students required PDA's to be connected to a kiosk that disseminated the information. This did not meet the objective, implement course-required software easily. Nor did the PDA's satisfactorily meet student wants with respect to screen size and flexibility to run different software.

The third alternative was to implement a laptop program. Of the three main laptop program choices considered, the two that involved students purchasing laptops from vendors directly (either any vendor or a specific vendor) were considered inappropriate for the needs of the college. Under both of those programs, students had to take care of any software or hardware malfunctions themselves and so at times could show up to class without the proper software or even a laptop. At universities using the third choice, typically the campus provided onsite support and a temporary replacement when a laptop was being serviced. The committee felt the objective, enhance learning across the curriculum, would be difficult to meet if faculty could not rely on students having a laptop or the proper software loaded and up to date.

In order to gather more cost and service information on laptops, a Request for Proposal was developed in which minimum specifications based on student and IT staff input were listed and sent to vendors. After reviewing the proposals, three vendors were invited to campus for presentations and more in-depth analysis. At this point, IT staff loaded a specific software program onto each of the demonstration laptops. This program accounted for differences in hardware capabilities and rated the laptops according to performance measurements. Thus, consistent performance comparisons were possible across the various laptops.

The performance ratings of each laptop were considered along with the impressions of the committee regarding the degree to which each laptop met the various objectives. Although the performance ratings were similar, the total cost of ownership differed significantly among the laptops. In one instance, the proposed laptop did not meet the first objective. It did however, meet or exceed all other objectives. For example, disassembling the laptop to simulate a service request required significantly less time than the others under consideration. Based on its ability to meet the most objectives, a specific vendor was selected.

\section{Step 5: Implement, Monitor, And Adjust}

Implementing the laptop program affected several university offices in addition to the IT group and the College of Business and Economics, which is one reason it was important to form a stakeholder-based team to address the original problem. For example, Student Registration was needed to identify eligible incoming business students, Financial Aid had to incorporate the program fee, Purchasing and Contracts needed to formalize the agreement and arrange delivery of the laptops, while Outreach and Public Relations helped inform prospective incoming freshmen and current students of the mandatory program. Also to help with the implementation, the IT group restructured 
internally to handle the new responsibilities and tasks required to accept delivery of the laptops from the vendor, image them with the required software, deliver them to students, and administer the program long-term through a dedicated service center.

The laptop program was monitored in a variety of ways. A tracking system was created by the IT group and used at the service desk to develop a database on the history of individual students and their laptops. This monitoring helped identify patterns in problematic laptops separate from students simply misusing their laptops. For instance, the tracking system allowed the service desk to quickly recognize and deal with a few systemic software and hardware problems that occurred the first semester of laptop implementation. In addition, the service desk staff documented problems and questions that came to them from faculty and students and then used this feedback to create and deliver tutorials through brown-bag lunch sessions. The brown-bag sessions helped keep students informed about laptop maintenance, virus prevention, and different software functionalities. Last, a survey was conducted following the first semester of implementation to prepare for the second round of administering laptops. (Results are discussed in the next section.)

The monitoring produced valuable information that highlighted the need for important adjustments to be made to the program on practically a continual basis. Indeed, at certain times adjustments were made to the tracking system at the service desk on a daily basis, such as when there was software problems in the first semester and usage/failure statistics needed to be collected. Adjustments on a monthly basis were made as the size of the program expanded over time from higher enrollments and students elsewhere on campus opting into the laptop program, as upgrades in software and hardware occurred, and to eventually accommodate a university-wide laptop program.

Another adjustment that occurred as a result of monitoring was that a particular support tool software program, one that conducted automatic back-ups of the system, was uninstalled. Interestingly, removing this program conflicted with the highly durable objective, which required the technology device to maintain itself to a certain degree. However, feedback showing students felt cheated by this software because it reduced total memory available was so strong that the IT staff believed the long-term viability of the laptop program was in jeopardy if the software remained.

\section{INSIGHTS TO THE PROCESS FRAMEWORK}

We found the RDMM to be an effective and useful decision-making tool in general. Next, we share insights particular to each of the five steps that we gained as a result of applying it to select a wireless tool within a university setting. It is noteworthy that several of the following insights emphasize the importance of involving stakeholders rather than relying on an individual program director or campus office.

An insight to the first step (Define the problem or opportunity) is that it is critical to understand the scope and depth of the problem. While the problem may appear straightforward, e.g., find a cost-efficient alternative to computer labs, input from representatives across the campus can influence the nature of the problem. For example, involving Financial Aid and Purchasing shortened the time-frame of our problem, by altering whether the problem existed one, two, or three semesters into the future, and limited its depth by reducing flexibility in potential contract agreements and possible overall solutions. Including the Registrar expanded the scope of the problem because the office refined its system, enabling the college to more easily track transfers, drop-outs, study abroads, part-timers, etc., which meant more students needed to be accommodated.

We developed two insights into the second step (Set objectives and criteria for a solution). One, keeping the student population informed of this step in particular is necessary to help manage misunderstandings and perceptions. In addition to the decision-making team including a representative from the student newspaper throughout the entire process, the team also gathered input from and made presentations to the student government and various student living groups. We found it especially important for students to understand the 'total cost of ownership' concept, because only then could they appreciate why items were included or excluded in the criteria and how final cost estimates reflected valuable service guarantees (e.g., availability of loaner laptops) and software packages, which caused estimated prices to be higher than those students found when looking at the prices of individual laptops online. 
Two, it is not necessary to rank all objectives developed, but it is very useful to have a primary objective or to rank at least a few of the objectives. This is because it is easy to be swayed during the evaluation phase by individual biases, which can support some objectives better than others, resulting in no obvious solution or method to differentiate between alternatives.

One insight to the third step (Generate alternatives) is that visits to other universities and colleges helped the team expand the list of alternatives beyond two (i.e., laptops in general and tablet-PC). The PDA was not a tool that the team considered until visiting a university that provided PDAs to its students. Further, the visits to other institutions resulted in identifying three variations on the more general laptop alternative.

Another insight to the third step is that generating alternatives can be very useful even if a particular solution seems relatively pre-determined to a subset of the decision-making committee. Needless to say, if after seriously comparing and contrasting the pros and cons of different alternatives the pre-determined solution is selected by all on the committee, then greater buy-in enabling easier implementation and acceptance is achieved. More importantly though, all involved gain a greater understanding of the strengths and weaknesses of the solution, which helps everyone better prepare for the final phase of implementation, monitoring, and adjustment.

It became clear to us that a few specific actions are useful during the fourth step (Evaluate and select) to overcome individual biases. For instance, following the process consistently by evaluating the ramifications of each alternative relative to each of the stated objectives is one way to overcome the halo effect (i.e., rating an alternative high because of a single characteristic or trait). This became apparent when the team evaluated the tablet-PC alternative against the complete list of objectives. The students and certain other stakeholders were intrigued by the tablet-PC (i.e., it rated will on the objective meets students wants), and thus, the alternative was given much attention during our discussions. However, because the team stuck to the process of evaluating each alternative against each objective the intriguing nature of the tablet-PC didn't outweigh its ratings on other objectives. As stated previously, highly durable and easy to service were two objectives deemed important by the decision making team because meeting these objectives significantly affected the ability to meet the cap on total cost of ownership. Because the tablet-PC did not rate well on the durability objective (a more important objective than meets students wants) ultimately the intrigue-factor was outweighed.

In addition, it was clear to us that during the fourth step in the process listening is a critical behavior and empathy is a critical perspective for all team members. Without listening and practicing empathy it is tempting to give in to personal, role, and job-related biases. For instance, in our experience it was easy at this point for faculty to underestimate student desires, for students to not understand the role of the tool in the classroom, and for IT staff to focus on infrastructure capabilities and service-related issues. A related insight is that this step benefits greatly from having an effective leader in the group and performing the second step well. That is, if individual team members latch on to different solutions, this can be managed by a leader who is able to help the members stick to the process of applying the pre-determined objectives to each alternative. Last, it is important for the committee to actually conduct evaluation tests and not rely on product claims. We found that our technology infrastructure and campus layout had enough unique features to alter the performance figures claimed by some of the vendors.

We gained several insights into the last step (Implement, monitor, and adjust). One, do not underestimate the benefits gained from stakeholder involvement in the overall decision-making process. Specifically, stakeholder involvement led to commitment to the chosen alternative and enthusiasm to implement the solution. Two, the quality of the collaborative efforts early on by faculty, directors, students, and various staff will in turn determine the quality of this step. Moreover, the collaborative efforts must not end when this step is reached if it is to be a useful and meaningful step. For example, the quality and range of laptop accessories supplied by our campus bookstore has helped promote satisfaction with the program. Also, Financial Aid and Registrar staff are able to field questions about program costs, filings, and scheduling related to the laptop program of the college.

Further, over-surveying the students is a potential outcome of enthusiastic efforts to monitor the program implementation. The result is poor quality and less useful feedback. Four, do not simply intend to monitor the program. Instead, plan for and formalize a monitoring and adjustment process. This will provide higher quality 
feedback and thus, speed the time in which adjustments are made. Five, continue monitoring both the solution and the overall problem since circumstances evolve. Because our problem and solution were tied to technology, we find that we are continually comparing the laptops to other vendors as well as other technologies. Finally, we found a significant benefit from staffing the laptop service desk with trained business students. In addition to understanding the technical aspects of the laptops, the service desk students are users of the laptops. They possess a high level of credibility with their fellow students, and by being in classes with other students they discover (and resolve) laptop problems that might otherwise go unreported.

\section{PRELIMINARY SURVEY RESULTS}

As another form of monitoring for Step 5 of the decision-making process, the IT student staff conducted two surveys after the first semester of the laptop program to roughly gauge changes in software skill levels and attitude toward the laptop program as a whole. One survey was given to students in the early part of the second semester ( $\mathrm{n}=$ $86,92 \%$ response rate), the other at the end of the same semester ( $\mathrm{n}=88,95 \%$ response rate). Both surveys asked students to self-report current skill levels with Microsoft Office programs, Windows XP, and other network application software, e.g., Internet Explorer, Netscape, and File Transfer Protocol, using a rating scale of 1 for Novice to 5 for Expert. Results are reported in Table 1.

Table 1: Student Survey Summary ${ }^{1}$

\begin{tabular}{|lccc|}
\hline Knowledge of: & Beginning of Semester & End of Semester & t-test of Mean Difference \\
\hline Word & 4.16 & 4.38 & 1.60 \\
Excel & 3.40 & 3.43 & 0.07 \\
Access & 1.86 & 1.97 & 0.63 \\
FrontPage & 1.90 & 2.06 & 0.81 \\
WindowsXP & 3.67 & 3.92 & $1.99^{*}$ \\
Network Applications & 3.67 & 3.97 & $2.07^{* *}$ \\
Usefulness & n/a & 3.94 & n/a \\
\hline
\end{tabular}

${ }^{1}$ Special thanks to the IXL Interns at the University of Idaho for conducting the student survey and analyzing the results.

$* \mathrm{p}<0.05, * * \mathrm{p}<0.01$

At the end of the semester, the average self-reported skill levels for Windows XP increased significantly to 3.92 from 3.67. The average skill level for network applications also increased significantly, to 3.97 from 3.67. There were no significant changes in self-reported skill levels for Word, Excel, Access, or FrontPage. One question was added to the second survey about the usefulness of the laptop program for course learning and completing class assignments using a rating scale of 1 for Not Useful to 5 for Very Useful. It appears that students perceived the laptops to be useful for completing assignments and for learning $(\mu=3.94)$. Currently, more statistically sophisticated evaluations are being conducted to look for trends and changes in student skill levels, amount of time spent using the laptop, and perceptions regarding the effectiveness of the laptop program.

\section{RECOMMENDATIONS}

In addition to using a collaborative decision-making approach and the process framework described above, we offer several recommendations to universities considering implementing a laptop program. To avoid simply listing the suggestions, we classify our recommendations into three general categories: procedures, monitoring, and programmatic.

A suggestion for the roll-out procedure is to keep the orientation process short and offer it frequently within a compacted time frame. During our first roll-out students were required to pick up their laptops on one specific day and attend a two-hour orientation. Feedback showed the students were not as excited to learn all the in's-and-out's of their laptops as we were. As a result, during the second roll-out two days were made available, along with much shorter and more frequent orientation sessions. Soon the students will simply be provided their laptops, registered into our 
information technology system, and the service desk staff will screen any follow-up questions that arise throughout the semester.

We expected students would have considerable experience with computer viruses and be pro-active in combating them. We underestimated their levels of awareness for the nature and impact of computer viruses and found that viruses were gaining access to the university's technology infrastructure by 'guessing' very easy, old passwords set by students. We recommend stringent policies regarding the duration and complexity of passwords.

In a similar vein, we find that after summer break or prolonged vacations laptops can become infected once they are re-connected to the university systems because the laptops contain outdated protection software due to the lapse in time since the last connection. We advise establishing a procedure whereby students returning from a lengthy break are provided a secure environment in which to update security patches for viruses.

We have three suggestions related to monitoring activities. In addition to a formal monitoring process, the skills and attitudes of the students should be informally monitored through conscious efforts by select staff and faculty that ask students after classes, in the hallways, or during office hours about their experiences with their laptops. We found these numerous, informal discussions gave us a useful gauge of how the students used their laptops and felt about the program as a whole. Feedback from these impromptu conversations went to the IT staff at the service desk and to the faculty at a monthly meeting.

Countering that suggestion though, is the advice that it will take time for faculty and students to adjust to a laptop program, so don't jump at every complaint heard. It is necessary to recognize that some students and faculty will always have issues with technology, and it is important to be patient and to look for patterns among issues that are raised prior to taking significant action. Representatives from other schools told us of similar experiences where students and faculty "warmed up" to the laptops as they became more familiar with the tool and found uses for them.

Finally, monitoring processes need to be specifically developed for the software level, the hardware level, the service level, and the overall program level. Each of the levels has unique, but related challenges. Monitoring at each level helps isolate and identify patterns in issues and attribute them to the correct level. In addition, monitoring the different levels is especially useful when a program is new because any problems or issues, no matter how simple or complex they may be, can overwhelm faculty and students, making it more difficult to separate individual issues from system-wide issues.

The prior recommendation is certainly useful for any laptop program. However, we may not have developed it as early as we did were it not for other lessons we were learning with our general program. While there are many programmatic recommendations we would make based on our experience, we suspect several of them are driven by issues that arose directly as a result of the laptop program being implemented at the college only and as a pilot study for the university. That is to say, many challenges that we faced in the past three years appear linked to the fact that students receive the laptops in the third year of college and only days before they enter their junior-level business classes. Examples of such unintended consequences include students at this stage lack basic software skills for fundamental software packages, they tend to be distracted by the laptop rather than view it as another research or educational tool, and many students need to be reminded if not even taught to take care of their laptop in fundamental ways, such as dealing with spyware and trouble-shooting basic software glitches. To a large degree, these and other similar issues disappear by the second semester after a laptop roll-out, again indicating that these challenges are experience-related and would be mitigated if students had the laptops from freshmen year.

To the extent that a university or college is considering a laptop program, to help ensure success, we recommend following a rational decision making model that incorporates pertinent stakeholders and implementation of the program as widely and early in the academic career of students as possible. Other factors beyond the scope of this paper to consider once implemented, are establishing expectations with respect to software skills, laptop etiquette in the classroom, using the laptop as a research and study tool, and assuming responsibility for the care and maintenance of the laptop. 


\section{ENDNOTES}

1. J. D. Thompson, Organizations in Action (New York: McGraw-Hill, 1967).

2. J. G. March and H. A. Simon, Organizations (New York: Wiley, 1958).

3. G. G. Dess and D. W. Beard, Dimensions of Organizational Task Environments, Administrative Science Quarterly, Vol. 29, No. 1, 1984, pp. 52-73.

4. D. Elmuti, Self-managed Work Teams Approach: Creative Management Tool or a Fad? Management Decision, Vol. 35, No. 3, 1997, pp. 233-239.

5. B. F. Daily and S. Huang, Achieving Sustainability Through Attention to Human Resource Factors in Environmental Management, International Journal of Operations and Production Management, Vo. 21, No. 12, 2001, pp. 1539-1554.

6. D. Strauss and P. Milton, Collaborative Decision Making, T\&D, Vol. 57, No. 7, 2003, pp. 70-73.

7. J. G. March and H. A. Simon, Organizations (New York: Wiley, 1958).

8. D. Kahneman and A. Tversky, Judgment Under Uncertainty (Cambridge: Cambridge University Press, 1982).

9. M. A. Neale and M. H. Bazerman, Cognition and Rationality in Negotiation (New York: Free Press, 1991).

10. D. Levi, Group Dynamics for Teams (Thousand-Oaks: Sage Publications, 2001).

11. V. L. Patel and J. F. Arocha, Linking Expertise and Naturalistic Decision Making, (Mahwah: Lawrence Erlbaum Associates, 2001).

12. S. Asch, Opinions and Social Pressure, Scientific American, Vol. 193, No. 5, 1955, pp. 31-35.

13. S. Milgram, Obedience to Authority (New York: Harper \& Row, 1974).

14. C. Falbe and G. Yukl, Consequences for Managers Using Single Influence Tactics and Combination of Tactics, Academy of Management Journal, Vol. 35, No. 3, 1992, pp. 638-652.

15. D. Levi, Group Dynamics for Teams (Thousand-Oaks: Sage Publications, 2001).

16. J. Dewey, How We Think (Boston: D. C. Heath \& Co, 1910).

17. C. H. Kepner and B. B. Tregoe, The Rational Manager: A Systematic Approach to Problem Solving and Decision Making (Princeton: McGraw Hill, 1965).

\section{FURTHER READINGS}

1. F. D. Davis, Perceived Usefulness, Perceived Ease of Use, and User Acceptance of Information Technology, MIS Quarterly, Vol. 13, No. 3, 1989, pp. 319-339.

2. O. T. Lenning and L. H. Ebbers, The Powerful Potential of Learning Communities ASHE-ERIC Higher Education Report Volume 26, No. 6, (Washington D. D.: The George Washington University, Graduate School of Education and Human Development, 1999).

3. Katzenbach and D. K. Smith, The Wisdom of Teams: Creating High-Performance Organizations (Boston: Harvard Business School Press, 1993).

4. T. L. Griffith, Technology Features as Triggers for Sensemaking, Academy of Management Review, Vol. 24, No. 3, 1999, pp. 472-488. 